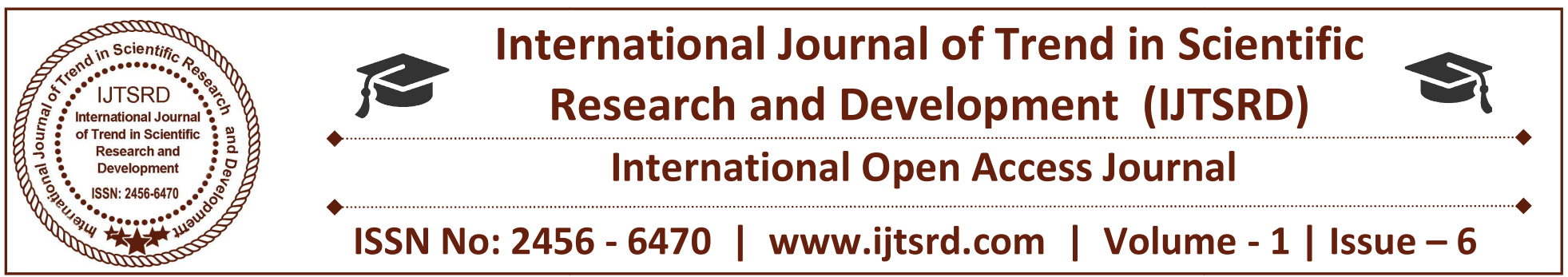

\title{
Factors Affecting Self Reported Physical Disability among Middle Aged Patients with Knee Osteoarthritis
}

\author{
Dr.Beulah Jebakani \\ Mtpg \& RIHS, Pondicherry
}

\author{
Dr.Vijayaraghavan \\ Research Department, \\ SaveethaUniversity. Pondicherry
}

\author{
Mrs.Megala Devi \\ Pondicherry
}

\begin{abstract}
Introduction: Identifying potential factors influencing the disability in patients with knee osteoarthritis is paramount for rehabilitation.

Objectives: To determine the factors that contributes to the symptoms of knee osteoarthritis.

Methods: Knee Injury and Osteoarthritis Outcome Score questionnaire (KOOS) was used to assess the physical disability. one hundred and twenty four patients (age range 50-65 years) were randomized to therapeutic exercise $(\mathrm{n}=62)$ and conventional group $(\mathrm{n}=62)$.

Results: The results of regression analysis revealed that age and BMI factors play a role in knee osteoarthritis.

Conclusion: The present study highlights the various factors that influence physical disability and thereby demonstrates to clinical researchers and practitioners that understanding and improving the quality of patient's well-being goes beyond simply treating the underlying clinical condition.
\end{abstract}

Keywords: Osteoarthritis, Quality of life, Exercises, Obesity

\section{INTRODUCTION}

Osteoarthritis (OA) causes disability affecting approximately $12 \%$ of those between $25-74$ years of age.[1,2]. Knee $\mathrm{OA}$ is multifactorial and can be divided into endogenous and exogenous risk factors. Endogenous risk factors include age, sex, heredity, Ethnic origin and postmenopausal changes. Exogenous risk factors include macro-trauma, repetitive micro-trauma; overweight, respective joint
Surgery and lifestyle factors[3]. Chronic aberrant and excessive knee joint loading is arguably the primary risk factor $[4,5]$.

The clinical manifestations of knee OA has a direct impact on physical, psychological, social, cognitive and general well-being of patient and can be evaluated in terms of knee related quality of life measures[ 6 ].The concept of Qol is critical due to the fact that patients vary greatly in their responses to identical stressors, such as pain. For the majority of patients, pain in OA is episodic in nature. The impact of depression on disability associated with $\mathrm{OA}$ is comparable to the effects of depression on cardiac ailments and other clinically important conditions[7]. Psychological well-being and anxiety have been found to be associated with pain and disability [8] Reducing depression seems to alter the levels of pain and disability in OA [9].

Articular degeneration is a key articular factor responsible for pain and disability in knee osteoarthritis $[10,11]$. Muscle weakness is the kinesiological factor that results in unstable joints. Mechanical stress on unstable joints leads to strain in innervated tissues, which may cause pain and disability. With regards to psychological factor, pain and disability are found to be associated with coping style, self-efficacy, beliefs and negative emotions [11, 12]. However it is unclear as to what extent each of these factors separately contributes. 


\section{Methods}

This is a part of research study conducted from April 2012 to December 2013 at Physical Medicine \& Rehabilitation Centre.

\section{Study design and study population}

A total of 124 patients were recruited and due to 6 dropouts during the intervention period, final analysis was done with 118 participants. The study population was randomly divided into a conventional physiotherapy and therapeutic exercise group respectively comprising of 59 patients each. Patients of diagnosed unilateral knee OA in the age group 5065 years with sufficient English/Tamil language skills to complete the assessment tools were included in the study.

Patients with neurological diseases, hypertensive patients, those with uncontrolled cardiopulmonary/respiratory diseases, patients unable to rise from and return to a chair without assistance, those with any additional muscular skeletal diseases/surgeries, psychiatric illness and liability to co-operate were excluded from the study.

Demographic data [age, gender, body mass index (BMI), duration of disease \& educational status] was obtained. Physical Disability was measured using KOOS scale. KOOS scale measures pain, symptoms, physical function, sport and recreation function, and knee-related quality of life. Standard versions of the KOOS scale were available for free in both English and Tamil. (http://www.koos.nu). The internal consistency range in knee osteoarthritis patients for KOOS Pain was 0.65-0.94, for KOOS Symptoms was 0.56-0.83, for KOOS Activities for Daily Living (ADL) was $0.78-0.97$, for KOOS Sport/Rec: 0.84-
0.98 , and for KOOS Quality of Life (QOL) was $0.71-$ $0.85[13]$.

Interventions: The treatment protocol for therapeutic exercise physiotherapy program was framed based on current published treatment recommendations of exercise programs for knee Osteoarthritis by American College of Rheumatology Subcommittee on Osteoarthritis Guidelines [14], American Geriatrics society [15], and evidence-based recommendations of an expert panel on delivering exercise therapy to knee OA patients [16].

Statistical analysis: For analysis of various factors affecting the parameters under study, logistic regression was used.

\section{Ethical committee consideration}

The study was approved by the Ethical committee. Letter of permission was taken from respective administration. Written informed participants were obtained. Privacy and confidentiality was maintained throughout the study period.

\section{Results}

The study included 118 participants after eliminating the dropouts. The age of the patients varied from 5065 years of age with maximum number of patients were in the age group of 50-55 years. A high percentage $(80.5 \%)$ of the participants was overweight with a BMI $\geq 25$. The entire study group was educated and had received a minimum of high school education. Table 1 demonstrates the split up of the demographic data.

Table1: Demographic characteristics

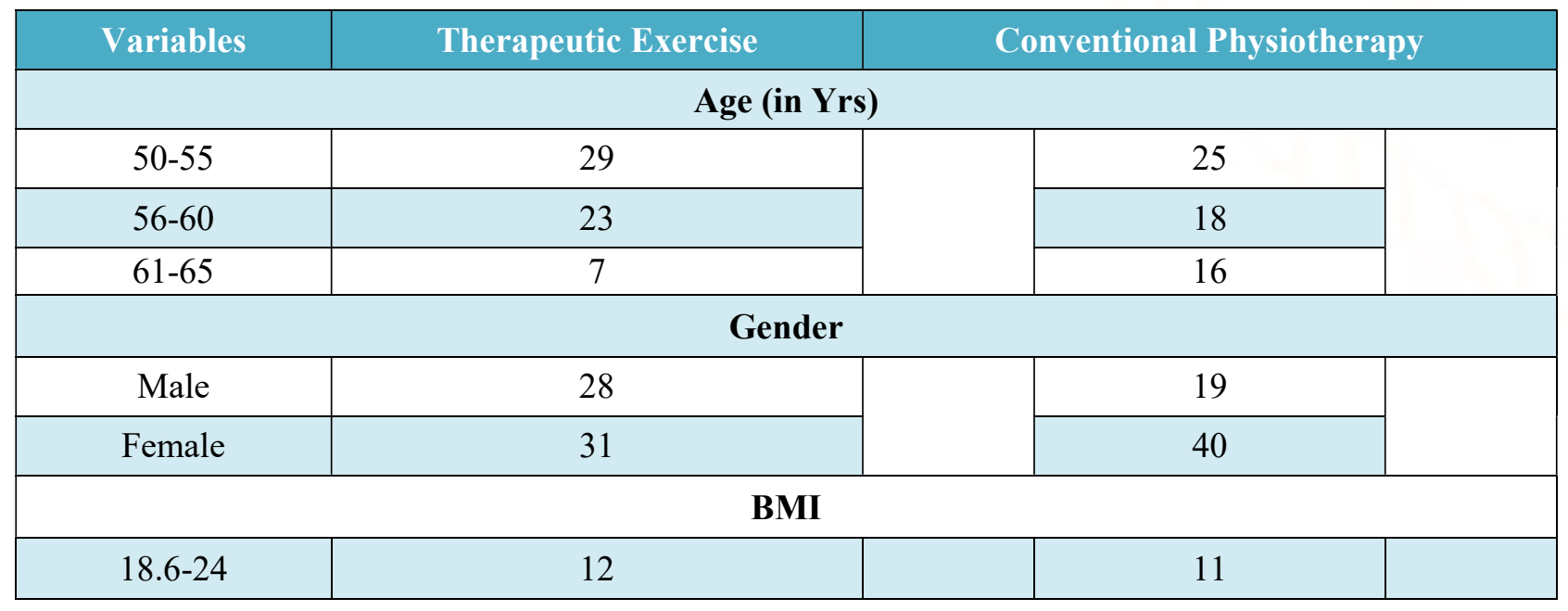


International Journal of Trend in Scientific Research and Development (IJTSRD) ISSN: 2456-6470

\begin{tabular}{|c|c|c|}
\hline $25-29$ & 23 & 31 \\
\hline$\geq 30$ & 24 & 17 \\
\hline \multicolumn{3}{|c|}{ Duration (in Yrs) } \\
\hline $3-6$ & 38 & 31 \\
\hline $7-12$ & 21 & 28 \\
\hline \multicolumn{3}{|c|}{ Education } \\
\hline High School & 39 & 44 \\
\hline Secondary & 9 & 2 \\
\hline Graduate & 11 & 13 \\
\hline
\end{tabular}

Logistic regression analysis showed age $(\mathrm{p}=0.043)$ to be a significant factor in predicting mean pain KOOS score in the therapeutic exercise group (table 2) while none of the factors seemed to influence the pain KOOS score in the conventional group.

Table 2: Logistic Regression table showing the factors affecting physical disability(KOOS)-Pain

\begin{tabular}{|c|c|c|c|c|c|c|c|c|}
\hline & & & & & & & \multicolumn{2}{|c|}{$\begin{array}{l}95 \% \\
\text { C.I.forEXP(B) }\end{array}$} \\
\hline & Factors & B & S.E. & Wald & p & OR & Lower & Upper \\
\hline \multirow{11}{*}{$\begin{array}{l}\text { Therapeutic } \\
\text { Group }\end{array}$} & Age & 1.311 & .648 & 4.085 & 0.043 & 3.709 & 1.041 & 13.219 \\
\hline & Gender & -1.654 & 1.200 & 1.900 & .168 & .191 & .018 & 2.010 \\
\hline & Occupation & -1.810 & 1.097 & 2.722 & .099 & .164 & .019 & 1.405 \\
\hline & Education & -.755 & .743 & 1.033 & .309 & .470 & .110 & 2.015 \\
\hline & Pain & 1.228 & .668 & 3.381 & .066 & 3.415 & .922 & 12.648 \\
\hline & Site & .243 & .377 & .416 & .519 & 1.275 & .609 & 2.670 \\
\hline & Side & -.468 & .676 & .478 & .489 & .626 & .166 & 2.358 \\
\hline & BMI & .290 & .412 & .496 & .481 & 1.337 & .596 & 3.000 \\
\hline & Constant & 1.419 & 3.582 & .157 & .692 & 4.134 & & \\
\hline & Duration & .906 & .693 & 1.710 & .191 & 2.474 & .636 & 9.617 \\
\hline & Total & -.965 & .781 & 1.525 & .217 & .381 & .082 & 1.762 \\
\hline
\end{tabular}

\begin{tabular}{|l|l|l|l|l|l|l|l|l|}
\hline Conventional & Age & -.155 & .445 & .121 & .728 & .857 & .358 & 2.049 \\
& Gender & -20.1 & 14608 & .000 & .999 & .000 & .000 & \\
& Education & .165 & .838 & .039 & .844 & 1.179 & .228 & 6.096 \\
\cline { 2 - 10 } & Occupation & -20.1 & 14608 & .000 & .999 & .000 & .000 & \\
\cline { 2 - 9 } & Pain & -1.460 & .969 & 2.269 & .132 & .232 & .035 & 1.552 \\
\cline { 2 - 9 } & Site & .555 & .406 & 1.870 & .172 & 1.742 & .786 & 3.860 \\
\cline { 2 - 9 } & Side & .246 & .715 & .118 & .731 & 1.278 & .315 & 5.189 \\
\cline { 2 - 9 } & BMI & .654 & .557 & 1.378 & .240 & 1.923 & .645 & 5.730 \\
& Duration & .035 & .709 & .002 & .960 & 1.036 & .258 & 4.161 \\
\hline
\end{tabular}

Regression analysis of the factors affecting KOOS symptom subscale showed that the duration of the pain 
International Journal of Trend in Scientific Research and Development (IJTSRD) ISSN: 2456-6470 $(p=0.004)$ was a significant predictor of KOOS symptom subscale in the therapeutic group. Age $(p=0.049)$ was a significant factor influencing the KOOS- symptom subscale in the conventional group.(Table 3 )

Table 3: Logistic regression table showing the factors affecting physical disability (KOOS) -Symptom

\begin{tabular}{|c|c|c|c|c|c|c|c|c|}
\hline \multirow[t]{2}{*}{ Group } & \multirow{2}{*}{$\begin{array}{l}\text { Factors } \\
\text { Age }\end{array}$} & \multirow{2}{*}{$\begin{array}{l}\text { B } \\
-.748\end{array}$} & \multirow{2}{*}{$\begin{array}{l}\text { S.E. } \\
.576\end{array}$} & \multirow{2}{*}{$\begin{array}{l}\text { Wald } \\
1.682\end{array}$} & \multirow{2}{*}{$\begin{array}{l}\mathrm{p} \\
.195\end{array}$} & \multirow{2}{*}{$\begin{array}{l}\text { OR } \\
.474\end{array}$} & \multicolumn{2}{|c|}{$\begin{array}{l}\text { 95\% C.I.forEXP(B) } \\
\text { Lower } \\
\text { Upper }\end{array}$} \\
\hline & & & & & & & .153 & \\
\hline \multirow{10}{*}{$\begin{array}{l}\text { Therapeutic } \\
\text { group }\end{array}$} & Gender & .225 & 925 & 059 & 808 & 1253 & 204 & 7678 \\
\hline & Occupation & 1.636 & .890 & 3.383 & .066 & 5.136 & .898 & 29.368 \\
\hline & Education & -.535 & .807 & .439 & .508 & .586 & .120 & 2.850 \\
\hline & Pain & 1.481 & .785 & 3.555 & .059 & 4.396 & .943 & 20.491 \\
\hline & Site & .040 & .393 & .010 & .920 & 1.040 & .482 & 2.246 \\
\hline & Side & .022 & .703 & .001 & .975 & 1.022 & .258 & 4.052 \\
\hline & BMI & .532 & .424 & 1.576 & 209 & 1.703 & .742 & 3.908 \\
\hline & Constant & -8.039 & 3.599 & 4.990 & .025 & .000 & & \\
\hline & Duration & 2.273 & .782 & 8.441 & 0.004 & 9.709 & 2.095 & 44.996 \\
\hline & Total & -.988 & .865 & 1.306 & .253 & .372 & .068 & 2.027 \\
\hline
\end{tabular}

\begin{tabular}{|l|l|l|l|l|l|l|l|l|}
\hline \multirow{3}{*}{$\begin{array}{l}\text { Conventiona } \\
1 \text { group }\end{array}$} & Age & -1.397 & .710 & 3.874 & $\underline{0.049}$ & .247 & .062 & .994 \\
\cline { 2 - 9 } & Education & 1.400 & 1.064 & 1.731 & .188 & 4.056 & .504 & 32.659 \\
\cline { 2 - 9 } & Pain & -.921 & 1.151 & .641 & .424 & 1.647 & .484 & 5.601 \\
\cline { 2 - 9 } & Site & .653 & .489 & 1.785 & .182 & 1.921 & .737 & 5.008 \\
\cline { 2 - 9 } & Side & .618 & .916 & .455 & .500 & 1.855 & .308 & 11.169 \\
\cline { 2 - 9 } & BMI & .499 & .625 & .638 & .424 & 1.647 & .484 & 5.601 \\
\cline { 2 - 9 } & Duration & -.262 & .943 & .077 & .781 & .769 & .121 & 4.886 \\
\hline
\end{tabular}

As per the data documented in table 4 the physical disability scores (KOOS)-ADL subscale was not found to be statistically influenced by any of the factors in the therapeutic group, however the educational status $(p=0.04)$ and duration of the illness $(\mathrm{p}=0.015)$ seemed to statistically influence ADL in conventional physiotherapy group.

Table4: Logistic regression table showing factors affecting physical disability(KOOS) -ADL subscale

\begin{tabular}{|l|l|l|l|l|l|l|l|l|}
\hline & & & & & & \multicolumn{3}{c|}{$\begin{array}{l}95 \% \\
\text { EXP(B) }\end{array}$} \\
\hline Group & & B & S.E. & Wald & p & OR & Lower & Upper \\
\hline \multirow{2}{*}{$\begin{array}{l}\text { Therapeutic } \\
\text { group }\end{array}$} & Age & -.881 & .565 & 2.436 & .119 & .414 & .137 & 1.253 \\
\cline { 2 - 10 } & Gender & 1.445 & 1.660 & .759 & .384 & 4.244 & .164 & 109.733 \\
\cline { 2 - 10 } & Occupation & 1.586 & 1.492 & 1.130 & .288 & 4.884 & .262 & 90.964 \\
\cline { 2 - 9 } & Education & .792 & .839 & .890 & .345 & 2.207 & .426 & 11.432 \\
\cline { 2 - 9 } & Pain & .242 & .735 & .109 & .742 & 1.274 & .302 & 5.375 \\
\cline { 2 - 9 } & Site & -.163 & .385 & .180 & .671 & .849 & .399 & 1.806 \\
\hline
\end{tabular}


International Journal of Trend in Scientific Research and Development (IJTSRD) ISSN: 2456-6470

\begin{tabular}{|l|l|l|l|l|l|l|l|l|}
\hline \multirow{5}{*}{} & Side & -.675 & .742 & .826 & .364 & .509 & .119 & 2.183 \\
\cline { 2 - 9 } & BMI & -.174 & .445 & .154 & .695 & .840 & .351 & 2.008 \\
\cline { 2 - 9 } & Constant & .411 & 4.698 & .008 & .930 & 1.508 & & \\
\cline { 2 - 9 } & Duration & -.739 & .715 & 1.070 & .301 & .478 & .118 & 1.938 \\
\cline { 2 - 9 } & Total & -.801 & .730 & 1.204 & .272 & .449 & .107 & 1.877 \\
\hline \multirow{5}{*}{$\begin{array}{l}\text { Conventional } \\
\text { group }\end{array}$} & Age & -.423 & .436 & .942 & .332 & .655 & .279 & 1.539 \\
\cline { 2 - 9 } & Gender & 1.166 & 1.449 & .647 & .421 & 3.208 & .187 & 54.888 \\
\cline { 2 - 9 } & Occupation & -.216 & 1.152 & .035 & .851 & 1.241 & .130 & 11.861 \\
\cline { 2 - 9 } & Education & 1.763 & .859 & 4.208 & $\underline{0.04}$ & 5.828 & 1.082 & 31.396 \\
\cline { 2 - 9 } & Pain & -.069 & .800 & .007 & .931 & 1.071 & .223 & 5.139 \\
\cline { 2 - 9 } & Site & .565 & .398 & 2.018 & .155 & 1.760 & .807 & 3.837 \\
\cline { 2 - 9 } & Side & 1.103 & .706 & 2.439 & .118 & 3.013 & .755 & 12.025 \\
\cline { 2 - 9 } & BMI & .929 & .537 & 2.996 & .083 & 2.531 & .884 & 7.245 \\
\cline { 2 - 8 } & Duration & 1.762 & .725 & 5.903 & $\underline{0.015}$ & 5.823 & 1.406 & 24.123 \\
& Constant & 12.345 & 4.882 & 6.393 & .011 & .000 & & \\
\hline
\end{tabular}

BMI ( $p=0.009$ ) of the participants of the conventional group influenced the QOL subscale (table 5) of KOOS however none of the factors seemed to statistically influence the KOOS- QOL.

Table 5: Logistic regression table showing factors affecting physical disability(KOOS) -QOL subscale

\begin{tabular}{|c|c|c|c|c|c|c|c|c|}
\hline \multirow{2}{*}{ Group } & & \multirow[b]{2}{*}{ B } & \multirow[b]{2}{*}{ S.E. } & \multirow[b]{2}{*}{ Wald } & \multirow[b]{2}{*}{$\mathbf{p}$} & \multirow[b]{2}{*}{ OR } & \multicolumn{2}{|c|}{$\begin{array}{l}95 \% \text { C.I. for } \\
\operatorname{EXP(B)}\end{array}$} \\
\hline & & & & & & & Lower & Upper \\
\hline \multirow{9}{*}{$\begin{array}{l}\text { Therapeutic } \\
\text { Group }\end{array}$} & Age & -.424 & .501 & .714 & .398 & .655 & .241 & 1.749 \\
\hline & Gender & 1.388 & 1.003 & 2.916 & .166 & 4.008 & .561 & 28.611 \\
\hline & Occupation & .357 & .854 & .175 & .676 & 1.429 & .268 & 7.615 \\
\hline & Education & -.146 & .672 & .047 & .828 & 1.157 & 310 & 4.323 \\
\hline & Pain & 1.190 & .671 & 3.147 & .076 & 3.287 & .883 & 12.238 \\
\hline & Site & -.182 & .335 & .295 & .587 & .833 & .432 & 1.673 \\
\hline & Side & -.790 & .634 & 1.553 & .213 & .454 & .131 & 1.572 \\
\hline & $\begin{array}{l}\text { BMI } \\
\text { Duration }\end{array}$ & $\begin{array}{l}.126 \\
-.772\end{array}$ & $\begin{array}{l}.376 \\
676\end{array}$ & $\begin{array}{l}.112 \\
1.306\end{array}$ & $\begin{array}{l}.738 \\
.253\end{array}$ & $\begin{array}{l}1.134 \\
.462\end{array}$ & $\begin{array}{l}.543 \\
.123\end{array}$ & $\begin{array}{l}2.369 \\
1.737\end{array}$ \\
\hline & $\begin{array}{l}\text { Constant } \\
\text { Total }\end{array}$ & $\begin{array}{l}-1.460 \\
.185 \\
\end{array}$ & $\begin{array}{l}3.205 \\
.639 \\
\end{array}$ & $\begin{array}{l}.208 \\
.084 \\
\end{array}$ & $\begin{array}{l}.649 \\
.772 \\
\end{array}$ & $\begin{array}{l}.232 \\
1.203 \\
\end{array}$ & .344 & 4.213 \\
\hline \multirow{8}{*}{$\begin{array}{l}\text { Conventional } \\
\text { group }\end{array}$} & Age & -.206 & .413 & .248 & .619 & .814 & .362 & 1.830 \\
\hline & Gender & 2.507 & 1.396 & 3.228 & .072 & 12.272 & .796 & 189.177 \\
\hline & Occupation & .914 & 1.031 & .786 & .375 & 2.495 & .330 & 18.838 \\
\hline & Education & -.049 & .799 & .004 & .951 & .952 & .199 & 4.558 \\
\hline & Pain & -.575 & .778 & .532 & .466 & .563 & .120 & 2.637 \\
\hline & Site & .467 & .387 & 1.460 & .227 & 1.596 & .748 & 3.406 \\
\hline & Side & .365 & .670 & .296 & .586 & 1.440 & .387 & 5.356 \\
\hline & $\begin{array}{l}\text { BMI } \\
\text { Duration }\end{array}$ & $\begin{array}{l}1.532 \\
.455\end{array}$ & $\begin{array}{l}.586 \\
.664\end{array}$ & $\begin{array}{l}6.827 \\
.470\end{array}$ & $\frac{0.009}{.493}$ & $\begin{array}{l}4.625 \\
1.577\end{array}$ & $\begin{array}{l}1.446 \\
.429\end{array}$ & $\begin{array}{l}14.591 \\
5.792\end{array}$ \\
\hline
\end{tabular}




\begin{tabular}{|l|l|l|l|l|l|l|l|l|}
\hline & Constant & -11.932 & 4.712 & 6.411 & .011 & .000 & & \\
\hline
\end{tabular}

\section{Discussion}

Osteoarthritis (OA) is a disease for which the prevalence, risk factors, clinical manifestations and prognosis vary according to the joints affected. The degradation of articular cartilage leads to joint pain and difficulty in movement such as in knee OA[17].

According to our study the condition was most prevalent in the age group of 50-55 years, suggesting the prevalence of $\mathrm{OA}$ in the late middle age group. CDC estimates $47.5 \%$ of adult population $\geq 60$ years in the US suffer from OA[18].

In the present study majority of the affected population were females. A number of studies have proved that the prevalence of knee OA in men is lower compared with women[19,20]. BMI was $\geq 25$ in $80.5 \%$ of the study population thereby indicating obesity to be an important factor to be associated with knee OA. Many studies results show a similar association between obesity and knee OA[21,22] .Obesity is associated with voluntary weakness of the quadriceps muscle[23].Weight reduction along with exercises has shown to improve function in patients with knee OA[24].

Mental health factors have a multifold relation to pain in OA. Vast majority of studies have found a positive correlation between depression and disability. Studies by Summers et al [25] and Salaffi et al [26] have found positive association of depression and disability in knee osteoarthritis. The above-mentioned studies show a clear-cut association of anxiety with depression, which is the preliminary cause for the physical disability. Any acute injury to the knee triggers anxiety and avoidance of movement as a protective response to prevent further damage to the knee. However long term anxiety is associated with persistent avoidance of motion resulting in loss of muscle bulk: Education and emotional support can help the patient conquer helplessness and alleviate the symptoms:[27] A study by Lin et al. [28] has shown a significant reduction in OA pain upon treatment of the co-existing depression.

Despite numerous studies, the etiology of OA remains elusive. Present study showed age and obesity to be the primary factors influencing the pain, symptomatology, physical disability and quality of life in patients with knee OA.

Symptoms associated with chronic conditions such as knee osteoarthritis typically fluctuate over time. Similarly the present study also proved that the duration of the disease significantly influenced the symptoms complex and physical disability associated with the disease.

Pharmacological and non-pharmacological measures are routinely utilized in the treatment of knee OA[29]. Oral and topical NSAIDs reduce pain in the short term compared with placebo, but can cause gastrointestinal, renal and cardiac adverse effects. Opioid analgesics reduce pain in knee osteoarthritis but they are associated with serious adverse effects so are not recommended for first-line treatment.. Exercise and physiotherapy modalities may reduce pain in people with knee osteoarthritis particularly in the initial stages. [30-36]

\section{Conclusion}

The study showed that knee osteoarthritis is primarily influenced by factors such as age, duration of the pain and BMI which, in turn showed a marked effect on the mean KOOS scores.

\section{REFERENCES:}

1. Peat G, McCarney R, Croft P. Knee pain and osteoarthritis in older adults: a review of community burden and current use of primaryhealth care. Ann Rheum Dis 2001 Feb;60:91-7

2. Jack Farr II, Larry E. Miller, Jon E. Block. Quality of Life in Patients with Knee Osteoarthritis: A Commentary on Nonsurgical and Surgical Treatments. The Open Orthopaedics Journal 2013; 7: 619-623.

3. Joern W, P. Michael, Klaus U, Schluter-Brust, Peer Eysel. The Epidemiology, Etiology, Diagnosis and Treatment of Osteoarthritis of the Knee. DtschArzteblInt 2010;107(9):152-62.

4. Waller C, Hayes D, Block JE, London NJ. Unload it: the key to the treatment of knee osteoarthritis. Knee Surg Sports TraumatolArthrosc 2011; 19(11): 1823-9.

5. Brandt KD, Dieppe P, Radin E. Etiopathogenesis 
of osteoarthritis. Med Clin North Am 2009; 93(1): $1-24, \mathrm{xv}$.

6. Dorr DA, Jones SS, Burns L, et al. Use of healthrelated, quality of-life metrics to predict mortality and hospitalizations in community-dwelling seniors. J Am GeriatrSoc 2006; 54(4): 667-73.

7. B.L. Wise, J. Niu, Y. Zhang, N. Wang, J.M. Jordan, E. Choy, D.J. Hunter. Psychological factors and their relation to osteoarthritis pain. Osteoarthritis and Cartilage 2010; 18: 883-887.

8. Creamer P, Lethbridge-Cejku M, Hochberg MC. Factors associated with functional impairment in symptomatic knee osteoarthritis. Rheumatology (Oxford) 2000;39(5):4906

9. Lin EH, Katon W, Von Korff M, Tang L, Williams Jr JW, Kroenke K, et al. Effect of improving depression care on pain and functional outcomes among older adults with arthritis: a randomized controlled trial. JAMA 2003;290(18):2428-9.

10. Ettinger WH, Afable RF. Physical disability from knee osteoarthritis: The Role of exercise as an intervention. Med Sci Sports Exerc. 1996;26:1435-40.

11. Dekker J, Boot B, Van Der Woude L, Birjlsma JWJ. Pain and disability in osteoarthritis: A review of behavioral mechanisms. J Behav Med 1992;15:189-214.

12. Rejeski WJ, Craven T, Ettinger WH, McFarlanc M, Shumaker S. Self efficacy and pain in disability with osteoarthritis of knee. J Gerontol Psych Sc 1996;51B: 24-9.

13. Collins, N. J., D. Misra, et al. Measures of knee function: International Knee Documentation Committee (IKDC) Subjective Knee Evaluation Form, Knee Injury and Osteoarthritis Outcome Score (KOOS), Knee Injury and Osteoarthritis Outcome Score Physical Function Short Form (KOOS-PS), Knee Outcome Survey Activities of Daily Living Scale (KOS-ADL), Lysholm Knee Scoring Scale, Oxford Knee Score (OKS), Western Ontario and McMaster Universities Osteoarthritis Index (WOMAC), Activity Rating Scale (ARS), and Tegner Activity Score (TAS). Arthritis care \& research. 2011; 63(11): S208-228

14. Hochberg MC, Altman RD, April KT, et al. American College of Rheumatology 2012 recommendations for the use of nonpharmacologic and pharmacologic therapies in osteoarthritis of the hand, hip, and knee. Arthritis Care Res. 2012;64:465-474.

15. American Geriatrics Society Panel on Exercise and Osteoarthritis. Exercise prescription for older adults with Osteoarthritis pain: Consensus Practice Recommendations. J Am GeriatrSoc 2001;49(6):808-823.

16. Roddy E, Zhang W, Doherty M, et al. Evidencebased recommendations for the role of exercise in the management of osteoarthritis of the hip or knee - the MOVE consensus. Rheumatology. 2005a;44:67-73.

17. Bhatia D, Bejarano $\mathrm{T}$, Novo $\mathrm{M}$. Current interventions in the management of knee osteoarthritis. J Pharm Bioallied Sci. 2013;5(1):30-8. doi: 10.4103/0975-7406.106561.

18. CDC.

www.cdc.gov/arthritis/basics/osteoarthritis.htm

19. Heidari B. Knee osteoarthritis prevalence, risk factors, pathogenesis and features: Part I. Caspian J Intern Med. 2011;2:205-12.

20. Litwic A, Edwards MH, Dennison EM, Cooper C. Epidemiology and burden of osteoarthritis. $\mathrm{Br}$ Med Bull 2013;105:185-199.

21. Slemenda c, Brandt KD, Heilman DK et al. Quadriceps weakness and osteoarthritis of the knee. Ann Intern Med 1997;127:97-104.

22. Martin K, Nicklas BJ, Bunyard LB et al. Weight loss and walking improve symptoms of knee osteoarthritis. Arthritis Rheum 1996;39:S225..

23. Summers M, Haley W, Reveille JO, Alarcon GS. Radiographic assessment and psychological variables as predictors of pain and functional impairment in osteoarthritis of the knee or hip. Arthritis Rheum 1988;31:204-9.

24. Salaffi F, Cavalieri F, Nolli M, Ferraccioli G. Analysis of disability in knee osteoarthritis. Relationship with age and psychological variables but not with radiographic score. J Rheumatol 1991;181581-6.

25. Creamer P, Lethbridge-Ceijku M, Hochberg C. Factors associated with functional impairment in symptomatic knee osteoarthritis. Rheumatology 2000;39:490-496

26. Lin EH, Katon W, Von Korff M, Tang L, Williams Jr JW, Kroenke K, et al. Effect of improving depression care on painand functional outcomes among older adults with arthritis: a randomized controlled trial. JAMA 2003;290(18):2428-9.

27. Zhang W, Moskowitz RW, Nuki G, Abramson S, Altman RD, Arden $\mathrm{N}$, et al. OARSI recommendations for the management of hip and knee osteoarthritis, Part I: Critical appraisal of existing treatment guidelines and systematic 
review of current research evidence. Osteoarthritis Cartilage 2007;15:981-1000.

28. Dias RC, Dias JM, Ramos LR. Impact of an exercise and walking protocol on quality of life for elderly people with OA of the knee. Physiother Res Int 2003;8:121-130.

29. Huang $\mathrm{MH}$, Lin YS, Yang RC, et al. A comparison of various therapeutic exercises on the functional status of patients with knee osteoarthritis. Semin Arthritis Rheum 2003;32:398-406.

30. Focht BC, Rejeski WJ, Ambrosius WT, et al. Exercise, self-efficacy, and mobility performance in overweight and obese older adults with knee osteoarthritis. Arthritis Rheum 200515;53:659665.

31. Thorstensson CA, Roos EM, Petersson IF, et al.
Six-week high-intensity exercise program for middle-aged patients with knee osteoarthritis: a randomized controlled trial. BMC Musculoskelet Disord 2005;6:27.

32. Thomas KS, Miller P, Doherty M, et al. Cost effectiveness of a two-year homeexercise program for the treatment of knee pain. Arthritis rheum 2005;53:388-394.

33. Beulah Jebakani, Gowri Sethu, Arumugam Pahinian,Megala Devi, Sashidharan Kotian \& Larissa Martha Sams,. Effects of Therapeutic Exercises on Pain and Physical Disability in Adults with Knee Osteoarthritis. Asian Journal of Scientific Research, (2015) 8, 74-79.

34. Huang MH, Yang RC, Lee CL, et al. Preliminary results of integrated therapy forpatients with knee osteoarthritis. Arthritis Rheum 2005;53:812-820. 